\section{Bulletin of Entomological}

Research

\section{cambridge.org/ber}

\section{Research Paper}

Cite this article: Campoy A, Lutsyk M, PérezBañón C, Rojo S (2022). Age-stage two-sex life table analysis of Eristalinus aeneus (Diptera, Syrphidae) reared with two different larval media. Bulletin of Entomological Research 112, 13-20. https://doi.org/10.1017/

\section{S0007485321000328}

Received: 21 October 2020

Revised: 12 March 2021

Accepted: 6 April 2021

First published online: 5 November 2021

\section{Keywords:}

Artificial rearing; brewery spent grain;

Eristalinus aeneus; hoverfly; life cycle

\section{Author for correspondence:}

Andrés Campoy, Email: andres.campoy@ua.es

\title{
Age-stage two-sex life table analysis of Eristalinus aeneus (Diptera, Syrphidae) reared with two different larval media
}

\section{Andrés Campoy (10, Mariya Lutsyk, Celeste Pérez-Bañón and Santos Rojo (D)}

Department of Environmental Sciences and Natural Resources, University of Alicante, PO Box 99, E-03080 Alicante, Spain

\begin{abstract}
Eristalinus aeneus (Scopoli, 1763) is a suitable candidate for artificial rearing due to its pollination efficiency and subcosmopolitan distribution. However, the high mortality found at the larval stage of this species needs to be overcome. In this research, two different larval media were used to study the life cycle of E. aeneus: brewery spent grain (BSG) from a local craft-beer factory and soaked oat grains (SOG). The age-stage, two-sex life table method was used to analyze the results, which were compared using the paired bootstrap test. The greatest mortality was found at the larval stage with both media. Individuals fed on SOG presented a shorter preadult developmental time (22.05 days) than those reared with BSG (26.97 days). This fact had a direct impact on the total preoviposition period, it being shorter with SOG (34.36 days) than BSG (38.29 days), although the second provided a larger total number of eggs (19,242 eggs) and a faster adult maturation (10.67 days). The population parameters indicated that both populations will display a positive growth under the studied conditions, being the mean generation time $(T)$ significantly shorter when using SOG (38.71 days) than BSG (45.95 days). Despite the preadult results pointing to SOG being a more efficient medium, the promising fecundity values provided by BSG, as well as it's lower cost and ecological benefits, suggest that this second medium could be improved and used as an alternative to SOG in the near future.
\end{abstract}

(c) The Author(s), 2021. Published by Cambridge University Press. This is an Open Access article, distributed under the terms of the Creative Commons AttributionNonCommercial-NoDerivatives licence (http:// creativecommons.org/licenses/by-nc-nd/4.0/), which permits non-commercial re-use, distribution, and reproduction in any medium, provided the original work is unaltered and is properly cited. The written permission of Cambridge University Press must be obtained for commercial re-use or in order to create a derivative work.

\section{CAMBRIDGE}

\section{Introduction}

Eristalinus aeneus (Scopoli, 1763) belongs to the Syrphidae family, which is one of the largest families within the Diptera order (Thompson and Rotheray, 1998; Pape et al., 2011). This species is present almost worldwide except for the Neotropical and Antarctica regions. It is commonly associated with eutrophicated water bodies, slow-moving streams, rivers and even coastal lagoons. In southern Europe, it has also been recorded in association with wastewater treatment plants, sewage farms and irrigation ditches, and is considered synanthropic (Pérez-Bañón et al., 2003; Speight, 2020).

The larvae of this species are aquatic and saprophagous, feeding on microorganisms and organic particles by filtering the water (Mahmoud et al., 1999; Lobkova et al., 2007). They present an elongated anal segment, the posterior respiratory process, which explains their common name of 'rat-tailed maggots' (Hartley, 1961). The larval stage presents three developmental instars (L1, L2 and L3), which are usually differentiated by the moulting events. The relevance of this immature stage resides in its role as bio-indicator of polluted aquatic environments (Sommaggio, 1999; Thompson et al., 2010), as well as its efficiency as biodecomposer of organic matter (Abou-El-Ela et al., 1978; Lardé, 1990).

The adults of this family are highly adapted to flower rewards such as pollen and nectar, with the subfamily Eristalinae, in particular, being considered important pollinators (Golding and Edmunds, 2000; Pérez-Bañón, et al., 2003, 2007; Ssymank et al., 2008; Doyle et al., 2020). Despite the scarcity of studies that focus just on the pollination efficiency of E. aeneus, the large number of references made to this species as an important member of the pollinator community in both natural and artificial environments highlights its relevance (de la Bandera and Traveset, 2006; Saeed et al., 2008; Tanács et al., 2008; Sajjad and Saeed, 2010; Latif et al., 2019).

Its importance as a pollinating agent has promoted the artificial rearing of this species. Generally, most of the larval rearing media have been based on animal manure and/or different types of decaying cereals, such as rice, wheat, barley or oats (Abou-El-Ela et al., 1978; Gladis, 1994; Hurtado, 2013; Campoy et al., 2020a). The considerable mortality at the larval stage has been stated as one of the main problems associated with the artificial rearing of E. aeneus, especially during the first instar (Campoy et al., 2020a). For this reason, a better understanding of its larval feeding habits, as well as new rearing diets, are required to overcome this problem. 
A promising alternative rearing medium consists of by-products from other industries, for instance, brewing, which would reduce the cost associated with insect production while contributing to circular economy practices (Fillaudeau et al., 2006; Thomas and Rahman, 2006; Kerby and Vriesekoop, 2017). Some by-products from this industry are brewery spent grain (BSG) or yeast, which have already been used in the animal feed sector, mainly for ruminants, but also for poultry, fish and pigs (Szponar et al., 2003; Mussatto et al., 2006; Aliyu and Bala, 2011). BSG is an abundant low-cost by-product, with about 3.4 million tonnes being produced in Europe every year (Stojceska et al., 2008), and its management is a matter of concern at local, national and international levels (LIFE-Brewery, 2016). It is rich in proteins (around 20\%), carbohydrates, fibre, minerals and vitamins, among other beneficial nutrients, as well as being full of microorganisms (Kanauchi et al., 2001; Mussatto, 2009; Aliyu and Bala, 2011). The main problems associated with the use of BSG as animal feed are the high moisture content (80$85 \%)$ and its susceptibility to spoilage by microbial growth (Stojceska et al., 2008; Aliyu and Bala, 2011). However, both issues can be used for the rearing of eristaline syrphids since the larval stage is aquatic and microorganisms are their main source of food (Hartley, 1961; Rotheray, 1993).

In order to test and compare the efficiency of different rearing media, it is essential to conduct accurate monitoring and analysis of population performance. For this purpose, life table methods have proven to be appropriate (Carey, 1993; Eliopoulos, 2006). These methods provide a wide range of data related to the life cycle, survival rates, fecundity and population dynamics. Age-stage, two-sex life table theory, which was developed by Chi and Liu (1985) and Chi (1988), has been shown to be a suitable tool for conducting these studies (Chi et al., 2020), as it addresses some of the common problems associated with traditional life table analysis (Lewis, 1942; Leslie, 1945; Birch, 1948).

The objectives of this study were: (1) to study the biology and population dynamics of E. aeneus under artificial conditions; (2) to compare the biological parameters of E. aeneus when reared with two different larval media, aiming to discover which medium is more suitable for artificial rearing.

\section{Materials and methods}

\section{Rearing method for preimaginal stages (egg, larva and pupa)}

This research was conducted at the University of Alicante, where an artificial rearing protocol for E. aeneus is being developed. For the experiments, six random egg batches from the second laboratory generation were collected. Three egg batches were placed in a plastic container $\left(15 \times 23 \times 10.5 \mathrm{~cm}^{3}\right)$ with $200 \mathrm{~g}$ of BSG and the other three batches in a different container with $200 \mathrm{~g}$ of soaked oat grains (SOG). The methodology followed with the two populations was identical, replicating the experiment conducted by Campoy et al. (2020a). The whole experiment was carried out in a rearing chamber at $25 \pm 1^{\circ} \mathrm{C}$, with $50 \% \mathrm{RH}$ and a $12: 12$ (L:D) hours photoperiod.

After the first instar larvae hatch, 200 individuals from each container were collected with a soft paint brush and separated into groups of ten larvae. Each group was kept in a plastic container $\left(9.5 \times 15 \times 6 \mathrm{~cm}^{3}\right)$ with $60 \mathrm{~g}$ of their corresponding rearing medium and water, and in total 20 containers were used for each rearing medium. These containers were checked every day, which involved recording the mortality and monitoring the remaining larvae. When the larvae reached the third instar, the containers were placed inside plastic cages $\left(15 \times 23 \times 10.5 \mathrm{~cm}^{3}\right)$ containing a layer of sawdust, in which the larvae pupated once their development was finished. These pupae were collected and separated individually in Petri dishes every day until the adults emerged.

\section{Rearing method for the adult stage}

The adults were marked with a coloured dot on their thorax to identify the date of emergence, thus facilitating their monitoring. These dots were applied with a small paint brush using harmless waterproof paint of different colours. The marked adults were released in a bug-dorm $\left(40 \times 40 \times 40 \mathrm{~cm}^{3}\right)$ until the first egg batch was laid. At that moment it was assumed that most of the females had mated. During this period, the adults were provided with $5 \mathrm{~g}$ of fresh pollen, $10 \mathrm{~g}$ of sugar, $30 \mathrm{ml}$ of honey, water and $15 \mathrm{~g}$ of SOG as oviposition medium. Food and water were replaced every 2 days, while the oviposition medium was checked daily.

At this point, the males and females were separated into plastic cages $\left(14.5 \times 22.5 \times 13.5 \mathrm{~cm}^{3}\right)$. These adults were provided with $2 \mathrm{~g}$ of fresh pollen, $4 \mathrm{~g}$ of sugar, $5 \mathrm{ml}$ of honey, water and $5 \mathrm{~g}$ of oviposition medium (SOG). Both fecundity and mortality were measured daily. Fecundity was recorded as the number of oviposition and the number of eggs per oviposition.

\section{Life table analysis}

The age-stage, two-sex life table theory (Chi and Liu, 1985) and the method described by Chi (Chi, 1988; Chi et al., 2020) were used to analyze the raw data from both experiments. The analysis was carried out by means of user-friendly software, namely TWOSEX-MSChart (Chi, 2020), which was designed in Visual BASIC (Version 2020.06.16) for the Windows operating system, available at http://140.120.197.173/Ecology/prod02.htm (Chung Hsing University, Taichung, Taiwan). Different parameters were estimated for both populations of $E$. aeneus: the age-stage specific survival rate $\left(s_{x j}\right.$; where $x$ is age and $j$ is the stage), the mortality distribution $\left(p_{x j}\right)$, the age-specific survival rate $\left(l_{x}\right)$, the age-stage specific fecundity $\left(f_{x 4}\right)$, the age-specific fecundity $\left(m_{x}\right)$, the agespecific maternity $\left(l_{x} m_{x}\right)$, the total preoviposition period (TPOP), the adult preoviposition period (APOP), the age-stage life expectancy $\left(e_{x j}\right)$, and the reproductive value $\left(v_{x j}\right)$. Additionally, four population parameters were obtained: the intrinsic rate of increase $(r)$, the finite rate of increase $(\lambda)$, the net reproductive rate $\left(R_{0}\right)$ and the mean generation time $(T)$.

The main formulas used by the software to calculate these parameters are shown in table 1 . The mortality distribution $\left(p_{x j}\right)$, agespecific survival rate $\left(l_{x}\right)$ and age-specific fecundity $\left(m_{x}\right)$ were obtained following the equations presented by Chi and Liu (1985) and Chi (1988). The iterative bisection method based on the Euler-Lotka equation was used to calculate the intrinsic rate of increase $(r)$, with age indexed from 0 (Goodman, 1982; Burden and Faires, 2005). The age-stage life expectancy $\left(e_{x j}\right)$ was estimated according to the formula of Chi and $\mathrm{Su}$ (2006). The reproductive value $\left(v_{x j}\right)$ (Fisher, 1930) was obtained following the method of Huang and Chi (2011) and Tuan et al. $(2014 a, b)$.

\section{Statistical analysis}

The TWOSEX-MSChart software was also used to calculate means and standard errors by using the bootstrap technique. A total number of 100,000 bootstrap resamplings were conducted 
Table 1. Main parameters and formulas used to calculate them

\begin{tabular}{lll}
\hline Parameter & Abbreviation & Formula \\
\hline $\begin{array}{l}\text { Age-stage specific } \\
\text { survival rate }\end{array}$ & $s_{x j}$ & $s_{x j}=\frac{n_{x j}}{n_{01}}$ \\
\hline $\begin{array}{l}\text { Distribution of } \\
\text { mortality }\end{array}$ & $p_{x j}$ & $p_{x j}=s_{x j} q_{x j}$ \\
\hline $\begin{array}{l}\text { Age-specific survival } \\
\text { rate }\end{array}$ & $l_{x}$ & $l_{x}=\sum_{j=1}^{\beta} s_{x j}$ \\
\hline $\begin{array}{l}\text { Age-specific } \\
\text { fecundity }\end{array}$ & $m_{x}$ & $m_{x}=\frac{\sum_{j=1}^{\beta} s_{x j} f_{x j}}{\sum_{j=1}^{\beta} s_{x j}}$ \\
\hline $\begin{array}{l}\text { Net reproductive } \\
\text { rate }\end{array}$ & $R_{0}$ & $R_{0}=\sum_{x=0}^{\infty} l_{x} m_{x}$ \\
\hline $\begin{array}{l}\text { Intrinsic rate of } \\
\text { increase }\end{array}$ & $r$ & $\sum_{x=0}^{\infty} \mathrm{e}^{-r(x+1) l_{x} m_{x}=1}$ \\
\hline $\begin{array}{l}\text { Finite rate of } \\
\text { increase }\end{array}$ & $\lambda$ & $\lambda=e^{r}$ \\
\hline $\begin{array}{l}\text { Mean generation } \\
\text { time }\end{array}$ & $T$ & $T=\frac{\ln \left(R_{0}\right)}{r}$ \\
\hline $\begin{array}{l}\text { Age-stage life } \\
\text { expectancy }\end{array}$ & $e_{x j}$ & $V_{x j}=\frac{\mathrm{e}^{r(x+1)}}{s_{x j}} \sum_{i=x}^{\infty} \mathrm{e}^{-r(i+1)} \sum_{y=j}^{k} s_{i j}^{\prime} f_{i y}$ \\
\hline Reproductive value & $v_{x j} \sum_{i=x}^{m} s_{i j}^{\prime}$ \\
\hline
\end{tabular}

to ensure precise results (Akköprü et al., 2015). The paired bootstrap test based on confidence interval (Efron and Tibshirani, 1993; Smucker et al., 2007; Reddy and Chi, 2015; Sedighi et al., 2017) was used to compare the larval survival, pupal survival, preadult survival, developmental time, mean life history duration, adult longevity, fecundity, number of oviposition, APOP, TPOP and population parameters between the two tested rearing media. Differences between male and female longevity for each rearing medium were also compared.

\section{Results}

\section{Life cycle}

The time of development for each stage, the adult longevity of both sexes and the mean life history duration were calculated for each population of $E$. aeneus using two different rearing media (table 2). Significant differences were only found between the larval stage and the total preadult stage (egg, larva and pupa) $(P<0.05)$, with these being shorter in general when SOG was used as the rearing medium.

No statistical differences were found in adult longevity, even when comparing males and females separately $(P>0.05)$. The total mean life history duration was also similar regardless of the rearing media $(P>0.05)$ (table 2$)$.

\section{Survival rate, distribution of mortality and life expectancy}

Both the age-stage survival rate $\left(s_{x j}\right)$ (fig. 1) and the distribution of mortality $\left(p_{x j}\right)$ (fig. 2 ) revealed that the highest mortality in the two populations is found in the larval stage (50.5\% in BSG and $46.5 \%$ in SOG), although the mortality distributions are different. When SOG was used as the main larval diet, the greatest mortality by far was on the 3rd day (2nd day in larval stage, L1), when $27.5 \%$ of the whole population died. In the case of BSG, the mortality was more scattered, with $12.5 \%$ dying on the 3rd day (2nd day in larval stage, L1), followed by a continuous increment of mortality at the end of this stage, reaching its maximum on the 19 th day, when $6 \%$ of the population died. The mortality distribution was more noteworthy in the pupal stage when $17.5 \%$ of the BSG population died in contrast with the figure of $6 \%$ found in SOG. The overlapping observed in figs 1 and 2 corresponds to the variable development among individuals, which results in them reaching the next developmental stage at different ages. Despite the variability in the mortality distribution, no significant differences were found in the larval survival rate using the two-rearing media $(P>0.05)$. However, differences between the populations were observed when comparing the survival rate of the pupal stage and the total preadult stage $(P<0.05)$.

The age-stage life expectancy $\left(e_{x j}\right)$ of a newborn was equal in the two experiments (28.65 d) (fig. 3). When BSG was used, the highest life expectancy was found to occur 2 days after the emergence of the male adults (27th day), $32.93 \mathrm{~d}$, followed by the day after the first mortality event in the larval stage (4th day), $29.31 \mathrm{~d}$ (fig. 3a). When E. aeneus was reared with SOG, the highest life expectancy in the adult stage was found to occur on the day of adult emergence (20th day) in both sexes, $29.64 \mathrm{~d}$ and $31.37 \mathrm{~d}$ for females and males, respectively. However, the highest peak during the whole life cycle was found in the larval stage, $35.37 \mathrm{~d}$ (fig. 3b), one day after the critical mortality event mentioned above (4th day).

\section{Reproductive parameters}

Different reproductive parameters were calculated for both populations: the mean age-stage specific fecundity $\left(f_{x 4}\right)$, the maximum daily fecundity, the maximum total fecundity and the mean number of oviposition (table 3). Mean fecundity and the number of oviposition were higher in the population reared with BSG, in fact, the total egg production of this population was 19,242 eggs, meanwhile the population reared with SOG only laid 15,116 eggs, yet no significant differences were found between the two populations $(P>0.05)$. The number of females that reached fertile age was similar: 21 out of 36 in the case of the population reared with BSG, and 25 out of 44 when reared using SOG.

The APOP and TPOP were significantly different $(P<0.05)$ between the populations (table 3). Despite the APOP being shorter when using BSG, pointing at a faster reproductive adult maturation, the TPOP was longer, considering the extended preadult developmental time found when this rearing medium was used.

The age-specific survival rate $\left(l_{x}\right)$, the age-stage specific fecundity $\left(f_{x 4}\right)$, the age-specific fecundity $\left(m_{x}\right)$ and the agespecific maternity $\left(l_{x} m_{x}\right)$ of $E$. aeneus reared with SOG and BSG are shown in fig. 4 . The population reared with BSG displayed a fertile age-range between the 33rd and 81st day, with a large egg contribution between the 37th and 60th day, followed by two important fecundity events, with the highest fecundity being 79.14 eggs per female. This period ran from the 30th to the 97 th day when SOG was used. In this case, most of the egg 
Table 2. Developmental time and adult longevity of E. aeneus reared with brewery spent grains (BSG) and soaked oat grains (SOG)

\begin{tabular}{|c|c|c|c|c|c|c|c|}
\hline \multirow[b]{2}{*}{ Parameter } & \multirow[b]{2}{*}{ Stage } & \multicolumn{3}{|c|}{$B S G$} & \multicolumn{3}{|c|}{ SOG } \\
\hline & & $N$ & Mean \pm SE & Range & $N$ & Mean \pm SE & Range \\
\hline \multirow{2}{*}{ Developmental time (days) } & Larva & 99 & $16.22 \pm 0.193^{\mathrm{a}}$ & $13-23$ & 107 & $11.14 \pm 0.098^{\mathrm{b}}$ & $9-15$ \\
\hline & Pupa & 64 & $8.84 \pm 0.149^{\mathrm{a}}$ & $5-12$ & 95 & $8.96 \pm 0.065^{\mathrm{a}}$ & $8-10$ \\
\hline \multirow[t]{3}{*}{ Adult longevity (days) } & Male & 28 & $32.3 \pm 4.375^{\mathrm{ac}}$ & $2-87$ & 51 & $29.47 \pm 2.918^{\mathrm{ac}}$ & $2-78$ \\
\hline & Female & 36 & $24.52 \pm 3.187^{\text {ac }}$ & $1-66$ & 44 & $28.09 \pm 3.22^{\mathrm{ac}}$ & $2-100$ \\
\hline & Adult & 64 & $27.93 \pm 2.648^{\mathrm{a}}$ & $1-87$ & 95 & $28.83 \pm 2.156^{\mathrm{a}}$ & $2-100$ \\
\hline Mean life history duration (days) ${ }^{1}$ & & 64 & $54.9 \pm 2.634^{\mathrm{a}}$ & $26-112$ & 95 & $50.88 \pm 2.143^{\mathrm{a}}$ & $23-121$ \\
\hline
\end{tabular}

Means within rows followed by different letters ( $\mathrm{a}$ or $\mathrm{b})$ are significantly different $(P<0.05)$, as well as the longevity of male and female adults when reared using the same medium ( $\mathrm{c}$ or $\mathrm{d}$ ) Differences between parameters were evaluated by using paired bootstrap test.

${ }^{1}$ To calculate the mean life history duration, only those individuals that reached the adult stage were considered.

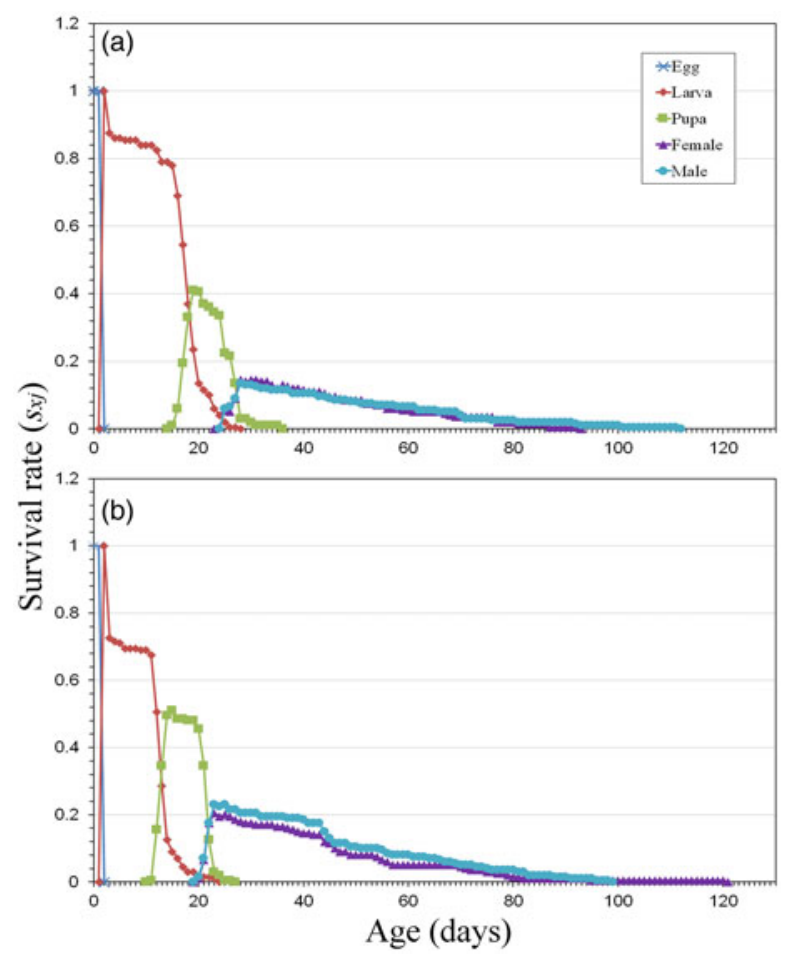

Figure 1. Age-stage survival rate $\left(s_{x j}\right)$ of $E$. aeneus reared with brewery spent grain, BSG (a) and soaked oat grains, SOG (b).

production occurred between the 30th and 47th day, and the highest fecundity was 38.38 eggs per female.

Although the reproductive value $\left(v_{x j}\right)$ considers the whole population (except for the male adults), higher values are usually found to be associated with females (fig. 5). Their contribution to population growth was located between the 24th and 81st day when BSG was used, with the highest peaks being reached on the 37th $\left(265.29 \mathrm{~d}^{-1}\right)$ and 44 th $\left(265.83 \mathrm{~d}^{-1}\right)$ days. Additionally, a high reproductive value was found in the pupal stage, reaching its maximum on the 35 th day $\left(222.19 \mathrm{~d}^{-1}\right)$ (fig. 5a). This peak corresponds to late-emerging females which contributed to the next generation. The population reared with SOG displayed a
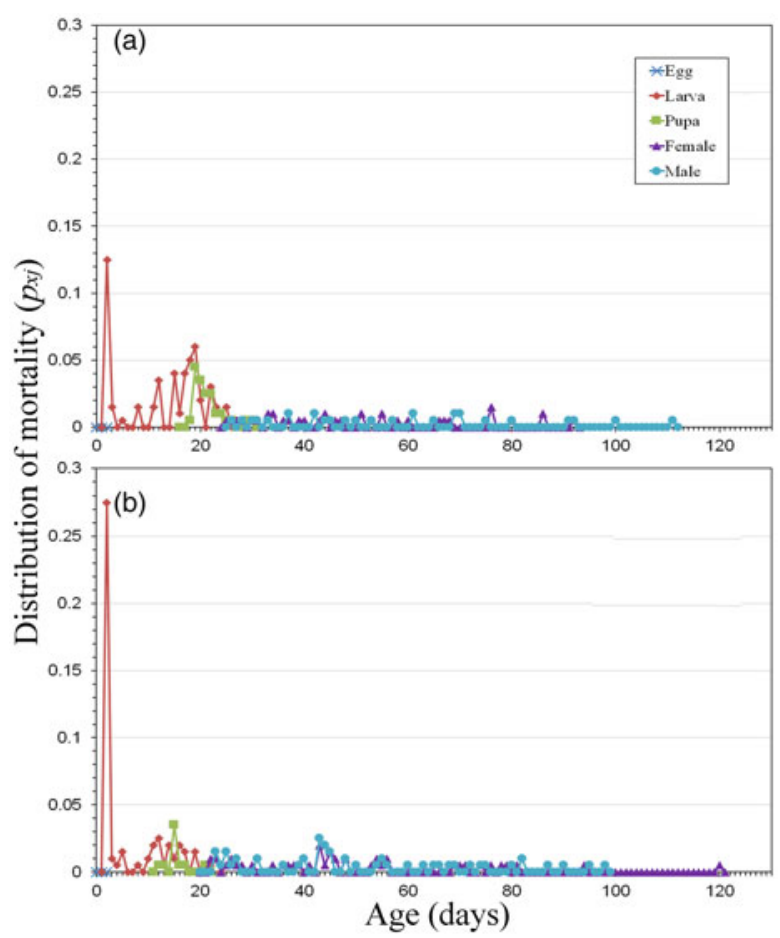

Figure 2. Mortality distribution $\left(p_{x j}\right)$ of $E$. aeneus reared with brewery spent grain, BSG (a), and soaked oat grains, SOG (b).

population growth between the 20th and 97th day, reaching the highest peak on the 30 th day $\left(183.35 \mathrm{~d}^{-1}\right)$ (fig. $5 \mathrm{~b}$ ).

\section{Population parameters}

The following population parameters were calculated for both populations: the intrinsic rate of increase $(r)$, the finite rate of increase $(\lambda)$, the net reproductive rate $\left(R_{0}\right)$ and the mean generation time $(T)$ (table 4 ). Both the intrinsic and the finite rates of increase indicated the positive growth of the two studied populations. The net reproductive rate was slightly higher in the population reared with BSG due to its higher fecundity, although no significant differences were found when comparing the intrinsic 


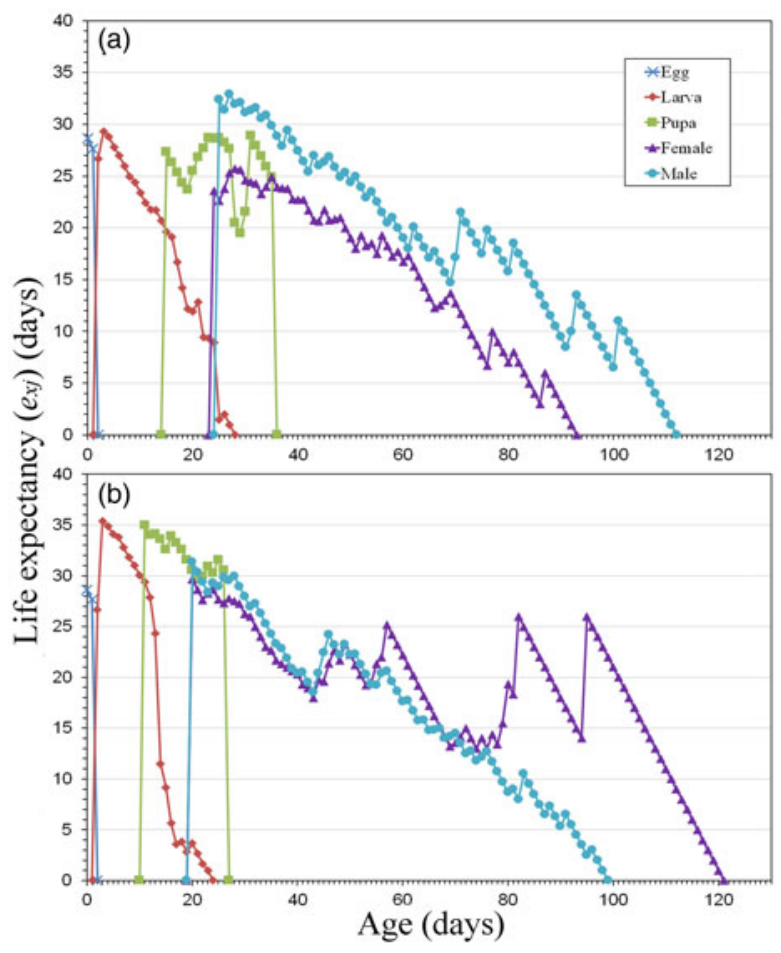

Figure 3. Age-stage life expectancy $\left(e_{x j}\right)$ of $E$. aeneus reared with brewery spent grain, BSG (a), and soaked oat grains, SOG (b).

rate of increase, the finite rate of increase or the net reproductive rate $(P>0.05)$. However, differences were observed when comparing the mean generation time $(P<0.05)$, this being shorter when E. aeneus was reared using SOG.

\section{Discussion}

\section{Life cycle}

The chosen rearing media had a direct influence on the larval developmental time, and thus on the total preadult duration. In general, the population reared with SOG displayed a faster larval development, allowing E. aeneus to reach the adult stage $4.92 \mathrm{~d}$ earlier (table 2). This difference could be explained as a variable nutritional content between both media, especially the microorganism populations that are present, as well as a totally different media consistency, although these factors were not assessed in this
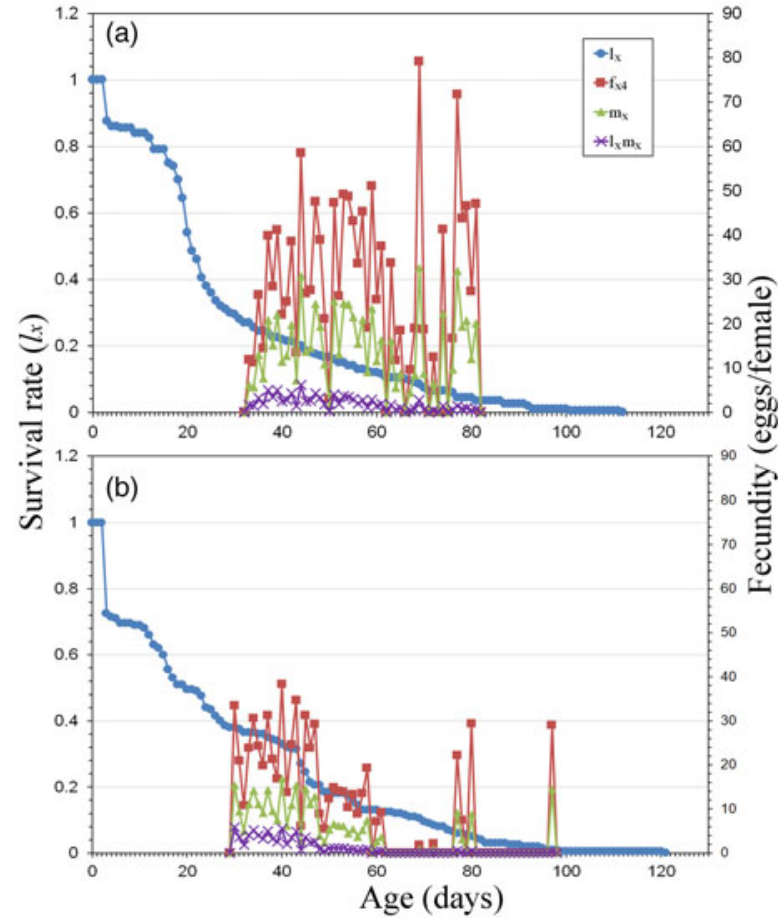

Figure 4. Age-specific survival rate $\left(I_{x}\right)$, age-stage fecundity $\left(f_{x 4}\right)$, age-specific fecundity $\left(m_{\mathrm{x}}\right)$ and age-specific maternity $\left(l_{\mathrm{x}} m_{\mathrm{x}}\right)$ of $E$. aeneus reared with brewery spent grain, BSG (a), and soaked oat grains, SOG (b).

experiment. The population of E. aeneus reared by Campoy et al. (2020a), using SOG under the same conditions $\left(25^{\circ} \mathrm{C}, 50 \% \mathrm{RH}\right.$ and 12:12 (L:D) h) and methodology, presented a larval and preadult duration (14.79 $\mathrm{d}$ and $25.24 \mathrm{~d}$, respectively) similar to the results obtained using BSG and slightly longer than those obtained with SOG in this study. This comparison confirms that fermented cereals, though effective, do not provide consistent results and the variability among populations cannot be underestimated. These differences between the two populations reared with SOG (in this study and Campoy et al. (2020a)) could correspond to the variable fermentation process, different populations of microorganisms or the genetic variability among individuals. However, since these factors have not been evaluated, no conclusions can be drawn in this regard. Future studies analysing the medium composition could shed light on this question.

Regarding adult longevity, no significant differences were found between the two populations, assuming that none of the

Table 3. Reproductive parameters of $E$. aeneus reared with brewery spent grains (BSG) and soaked oat grains (SOG)

\begin{tabular}{|c|c|c|c|c|c|c|}
\hline \multirow[b]{2}{*}{ Parameter } & \multicolumn{3}{|c|}{$B S G$} & \multicolumn{3}{|c|}{ SOG } \\
\hline & $N$ & Mean \pm SE & Range & $N$ & Mean \pm SE & Range \\
\hline Fecundity (eggs per female) & 36 & $534.04 \pm 128.57^{a}$ & $0-2773$ & 44 & $343.4 \pm 66.83^{a}$ & $0-1620$ \\
\hline Maximum daily fecundity (eggs per female) & & 330 & & & 450 & \\
\hline Maximum total fecundity (eggs per female) & & 2773 & & & 1620 & \\
\hline Oviposition (egg batches per female) & 21 & $6.66 \pm 1.21^{\mathrm{a}}$ & $1-22$ & 25 & $5.04 \pm 0.73^{a}$ & $1-18$ \\
\hline APOP (days) & 21 & $10.67 \pm 0.49^{b}$ & $7-16$ & 25 & $12.64 \pm 0.59^{\mathrm{a}}$ & $9-19$ \\
\hline TPOP (days) & 21 & $38.29 \pm 0.91^{\mathrm{a}}$ & $33-48$ & 25 & $34.36 \pm 0.67^{b}$ & $30-41$ \\
\hline
\end{tabular}

Means within rows followed by different letters ( $\mathrm{a}$ or $\mathrm{b}$ ) are significantly different $(P<0.05)$. Differences between parameters were evaluated by using paired bootstrap test. 

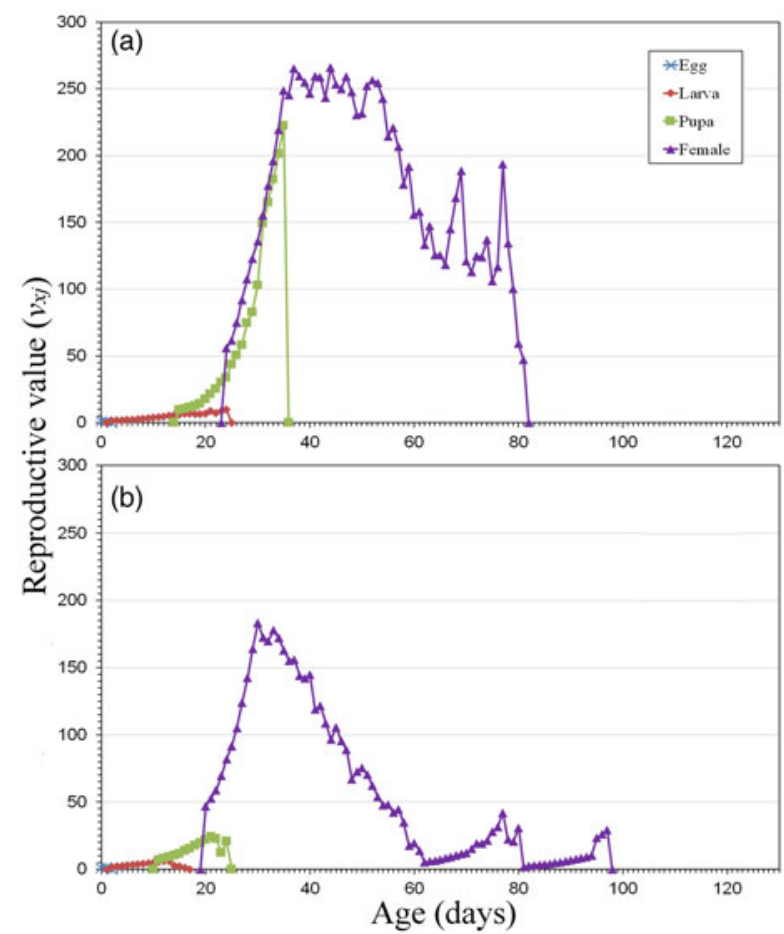

Figure 5. Age-stage reproductive value $\left(v_{x j}\right)$ of $E$. aeneus reared with brewery spent grain, BSG (a), and soaked oat grains, SOG (b).

Table 4. Population parameters of $E$. aeneus reared with brewery spent grains (BSG) and soaked oat grains (SOG)

\begin{tabular}{|c|c|c|}
\hline & $B S G$ & SOG \\
\hline Population parameters & Mean \pm SE & Mean \pm SE \\
\hline $\begin{array}{l}\text { Intrinsic rate of increase, } \\
r\left(\text { days }^{-1}\right)\end{array}$ & $0.099 \pm 0.006^{\mathrm{a}}$ & $0.111 \pm 0.007^{\mathrm{a}}$ \\
\hline $\begin{array}{l}\text { Finite rate of increase, } \\
\lambda\left(\text { days }^{-1}\right)\end{array}$ & $1.104 \pm 0.007^{\mathrm{a}}$ & $1.117 \pm 0.008^{\mathrm{a}}$ \\
\hline $\begin{array}{l}\text { Net reproductive rate, } R_{o} \\
\text { (offspring per individual) }\end{array}$ & $96.16 \pm 27.109^{a}$ & $75.51 \pm 17.707^{a}$ \\
\hline Mean generation time, $\boldsymbol{T}$ (days) & $45.95 \pm 1.458^{\mathrm{a}}$ & $38.71 \pm 0.904^{b}$ \\
\hline
\end{tabular}

Means within rows followed by different letters ( $\mathrm{a}$ or $\mathrm{b}$ ) are significantly different at $P<0.05$. Differences between parameters were evaluated by using paired bootstrap test.

chosen media negatively affects this parameter (table 2). In general, no significant differences were found between males and females, although it was found to be significant in the study of Campoy et al. (2020a).

\section{Survival rate, mortality distribution and life expectancy}

The mortality rate displayed by the larvae of both populations was similar, although its distribution varied (figs 1 and 2). This mortality was critical just after hatching, at the first larval instar, especially when SOG was used as the rearing medium (figs $1 \mathrm{~b}$ and $2 \mathrm{~b})$. This phenomenon was also observed by Campoy et al. (2020a). In the case of BSG, the mortality of the first instar was not as pronounced, but a steady increase in mortality was observed, reaching a second peak during the third larval instar (figs 1a and 2a). This is probably due to an adverse fermentation of the medium, which in this case had a harmful effect on the larvae in the long term. This fact was corroborated by the peak in mortality found at the beginning of the pupal stage, coinciding with the pupariation process, when hardening and tanning of the puparium takes place before reaching the actual pupal stage (Fraenkel and Bhaskaran, 1973; Campoy et al., 2020b). In this research, the prepupal phase (between pupariation and larvalpupal apolysis) was included as part of the pupal stage.

Although the highest life expectancy is commonly associated with the first day of the population, in these two media the highest peaks are found after noteworthy mortality events (Tuan et al., 2017), for instance on the 4th day (figs 2 and 3), one day after the critical mortality detected in the first larval instar in both populations, especially when SOG was used. The population reared with BSG stands out for being the one in which the male adults present the highest life expectancy since this was the long-lived stage. There are also two big troughs in the pupal stage. The first coincides with the mortality found in the pupariation process mentioned above, and the second corresponds to a high adult emergence event (fig. 3a). The population reared with SOG presents three unusual peaks in the female adult stage on the 57th, 82nd and 95th days. They correspond to three periods of stability (without mortality), with the 95th day being the most noteworthy when a single female survived for 25 days (fig. $3 b)$.

\section{Reproductive and population parameters}

The main significant differences between the two populations were found in the APOP and TPOP (table 3). The TPOP indicates that the population reared with SOG reached the fertile age significantly earlier. This difference can be mainly attributed to the shorter larval stage duration displayed by this population since female adults from the BSG medium showed a shorter APOP.

Even though no significant differences were found in the rest of the parameters analysed, the total production of eggs was $21.44 \%$ larger in the population reared with BSG (table 3 ). This difference suggests that adult fecundity could somehow be related to the larval diet; the fact that nutrient consumption and the conditions in which the larvae grow have an effect on adult performance and development has already been demonstrated (Aguila et al., 2013; Gobbi et al., 2013; Weldon et al., 2019). When the populations reared with SOG in this experiment and in Campoy et al. (2020a) are compared, we observe that the fecundity parameters in the latter study are much lower. In this case, where the larval medium and methodology are very similar, the main differences could be associated with other factors such as diet (the inclusion of honey in this study) or genetics (laboratory generation or genetic loss). Furthermore, the temperature also has an undeniable effect on fecundity, and especially on the maturation period. For example, Abou-El-Ela et al. (1978) found an APOP of 4 days at $32^{\circ} \mathrm{C}$, whereas Hurtado (2013) reported $17.23 \mathrm{~d}$ at $20^{\circ} \mathrm{C}$.

The figures for fecundity and reproductive value (figs 4 and 5) provide visual information about the abundance and distribution of egg production by females. The highest reproductive values are usually found between female adult emergence and the TPOP, highlighting the period when the greatest contribution to the next generation is expected. The population reared with SOG reached the highest reproductive value 7 days earlier than the population reared with BSG (on the 30th and 37th day, respectively). This fact is supported by the shorter TPOP and mean generation time $(T)$, as well as the slightly higher intrinsic $(r)$ and finite 
( $\lambda$ ) rates of increase. However, this faster development contrasts with a higher total production of eggs displayed by female adults reared with BSG. In fact, this population maintains a reproductive value above $200 \mathrm{~d}^{-1}$ between the 34 th and 57 th day (table 4 ).

\section{Conclusions}

In general, the population reared with SOG displayed a faster preadult development and a higher survival rate. However, these differences were compensated for by a larger number of eggs laid when BSG was chosen as the main larval medium. The relationship between larval diet and adult longevity/fecundity is still unclear in this species, since the results are variable and not significantly different, although the greater number of eggs and oviposition, as well as the more compact fecundity range and shorter APOP could point to some nutrients present in the BSG as being responsible of these noteworthy differences. However, more studies are required to accurately establish the effect of this rearing medium on the adult performance and fecundity of this species.

Considering all these biological and population parameters, it must be decided which aspect is preferable in the artificial rearing of this species: a faster development or a higher egg production. We believe that the BSG medium provides much better prospects since this medium has not been used before with eristalines and the methodology still has ample room for improvement; for instance, by adjusting the quantity of the product and the environmental conditions, or by analysing the medium to find which supplementary nutrients are required and how the fermentation process modifies the medium.

From an economic and ecological point of view, the use of BSG allows the inclusion of the larval rearing process as part of a circular economy, using by-products from a different industry, in contrast with the use of SOG, which implies the generation of a high volume of waste, since the oat grains are not directly consumed by the larvae. Additionally, BSG is a much cheaper option, which clearly benefits the artificial production of commercial pollinators. Further studies are required to obtain better parameters for using BSG or alternative by-products from other industries.

Acknowledgements. The current manuscript is part of a $\mathrm{PhD}$, written by Andrés Campoy Pomares at the University of Alicante (Spain). This project is funded by a FPU grant (FPU16-01985), provided by the Spanish Ministry of Universities (MIU).

\section{References}

Abou-El-Ela R, Taher MO and Nazer IO (1978) On the biology of Eristalis aeneus (Scopoli) in Saudi Arabia (Diptera: Syrphidae). Journal of the Faculty of Science, University of Riyadh 9, 73-86.

Aguila JR, Hoshizaki DK and Gibbs AG (2013) Contribution of larval nutrition to adult reproduction in Drosophila melanogaster. Journal of Experimental Biology 216, 399-406.

Akköprü EP, Atlihan R, Okut H and Chi H (2015) Demographic assessment of plant cultivar resistance to insect pests: a case study of the dusky-veined walnut aphid (Hemiptera: Callaphididae) on five walnut cultivars. Journal of Economic Entomology 108, 378-387.

Aliyu S and Bala M (2011) Brewer's spent grain: a review of its potentials and applications. African Journal of Biotechnology 10, 324-331.

Birch L (1948) The intrinsic rate of natural increase of an insect population. Journal of Animal Ecology 17, 15-26.

Burden RL and Faires JD (2005) Numerical Analysis. Boston, MA, USA: Brooks/Cole, Centage Learning.
Campoy A, Sáez L, Pérez-Bañón C and Rojo S (2020a) Demography and population parameters of two species of eristaline flower flies (Diptera, Syrphidae, Eristalini). Journal of Applied Entomology 144, 133-143.

Campoy A, Aracil A, Pérez-Bañón C and Rojo S (2020b) An in-depth study of the larval head skeleton and the external feeding structures related with the ingestion of food particles by the eristaline flower flies Eristalis tenax and Eristalinus aeneus. Entomologia Experimentalis et Applicata 281, 1436-1445.

Carey JR (1993) Applied Demography for Biologists with Special Emphasis on Insects. New York, USA: Oxford University Press.

Chi H (1988) Life-table analysis incorporating both sexes and variable development rate among individuals. Environmental Entomology 17, 26-34.

Chi H (2020) TWOSEX-MSChart: a computer program for the age-stage, twosex life table analysis (Version 2020.06.16) National Chung Hsing University, Taichun, Taiwan. Available at http://140.120.197.173/Ecology/ prod02.htm.

Chi H and Liu H (1985) Two new methods for the study of insect population ecology. Bulletin of the Institute of Zoology, Academia Sinica 24, 225-240.

Chi H and Su HY (2006) Age-stage, two-sex life tables of Aphidius gifuensis (Ashmead) (Hymenoptera: Braconidae) and its host Myzus persicae (Sulzer) (Homoptera: Aphididae) with mathematical proof of the relationship between female fecundity and the net reproductive rate. Environmental Entomology 35, 10-21.

Chi H, You MS, Atlıhan R, Smith CL, Kavousi A, Özgökçe MS, Güncan A, Tuan SJ, Fu JW, Xu YY, Zheng FQ, Ye BH, Chu D, Yu Y, Gharekhani G, Saska P, Gotoh T, Schneider MI, Bussaman P, Gökçe A and Liu TX (2020) Age-stage, two-sex life table: an introduction to theory, data analysis, and application. Entomologia Generalis 40, 103-124.

de la Bandera MC and Traveset A (2006) Breeding system and spatial variation in the pollination biology of the heterocarpic Thymelaea velutina (Thymelaeaceae). Plant Systematics and Evolution 257, 9-23.

Doyle T, Hawkes WLS, Massy R, Powney GD, Menz MHM and Wotton KR (2020) Pollination by hoverflies in the Anthropocene. Proceedings of the Royal Society B 287, 20200508.

Efron B and Tibshirani RJ (1993) An introduction to the Bootstrap. New York, NY, USA: Chapman and Hall.

Eliopoulos P (2006) Life tables of Venturia canescens (Hymenoptera: Ichneumonidae) parasitizing the Mediterranean flour moth (Lepidoptera: Pyralidae). Journal of Economic Entomology 99, 237-243.

Fillaudeau L, Blanpain-Avet P and Daufin G (2006) Water, wastewater and waste management in brewing industries. Journal of Cleaner Production 14, 463-471.

Fisher RA (1930) The Genetical Theory of Natural Selection. Oxford, UK: Clarendon Press.

Fraenkel G and Bhaskaran G (1973) Pupariation and pupation in cyclorrhaphous flies (Diptera): terminology and interpretation. Annals of the Entomological Society of America 66, 418-422.

Gladis T (1994) Laboratory rearing of some eristalines (Diptera, Syrphidae) and the possibility of their use in plant cultures. Verhandlungen der westdeutscher Entomologentag, 139-152, (in German, English summary).

Gobbi P, Martínez-Sánchez A and Rojo S (2013) The effects of larval diet on adult life-history traits of the black soldier fly, Hermetia illucens (Diptera: Stratiomyidae). European Journal of Entomology 110, 461-468.

Golding YC and Edmunds M (2000) Behavioural mimicry of honeybees (Apis mellifera) by droneflies (Diptera: Syrphidae: Eristalis sp.). Proceedings of the Royal Society of London 267, 903-909.

Goodman D (1982) Optimal life histories, optimal notation, and the value of reproductive value. The American Naturalist 119, 803-823.

Hartley JC (1961) A taxonomic account of the larvae of some British Syrphidae. Proceedings of the Zoological Society of London 186, 503-593.

Huang YB and Chi H (2011) The age-stage, two-sex life table with an offspring sex ratio dependent on female age. Journal of Agriculture and Forestry 60, 337-345.

Hurtado P (2013) Estudio del ciclo de vida de sírfidos eristalinos (Diptera, Syrphidae) y bases para su cría artificial (Doctoral dissertation). University of Alicante, Spain. Available at http://rua.ua.es/dspace/handle/ $10045 / 45586$.

Kanauchi O, Mitsuyama K and Araki Y (2001) Development of a functional germinated barley foodstuff from brewers' spent grain for the treatment of 
ulcerative colitis. Journal of the American Society of Brewing Chemists 59, $59-62$.

Kerby C and Vriesekoop F (2017) An overview of the utilisation of brewery By-products as generated by British Craft Breweries. Beverages 3, 24.

Lardé G (1990) Growth of Ornidia obesa (Diptera: Syrphidae) larvae on decomposing coffee pulp. Biological Wastes 34, 73-76.

Latif A, Malik SA, Saeed S, Iqbal N, Saeed Q, Khan KA, Ting C and Ghramh HA (2019) Diversity of pollinators and their role in the pollination biology of chickpea, Cicer arietinum L. (Fabaceae). Journal of Asia-Pacific Entomology 22, 597-601.

Leslie P (1945) On the use of matrices in certain population mathematics. Biometrika 33, 183-212.

Lewis EG (1942) On the generation and growth of a population. Sankhya 6, 93-96.

LIFE-Brewery (2016) New Strategies for Improving the Sustainability of Breweries: Full Waste Recovery for Aquaculture Feed (LIFE16 ENV/ES/ 000160). Brussels, Belgium: LIFE Europe.

Lobkova LE, Barinova ES, Dulov LE and Galchenko VF (2007) Interactions between larvae of the hoverfly Eristalinus sepulchralis and microorganisms in the hydrothermal springs of the Uzon caldera, Kamchatka. Microbiology (Reading, England) 76, 357-367.

Mahmoud M, Bahgat M, Zalat S and Dewedar A (1999) Eristalinus larvae and the role of bacteria in their feeding. Journal of the Union of Arab Biologists 11A (Zoology), 417-433.

Mussatto SI (2009) Biotechnological potential of brewing industry By-products. In Singh-Nee PN \& Pandey A (Eds), Biotechnology for Agro-Industrial Residues Utilization. Dordrecht, Netherlands: Springer, pp. 313-326.

Mussatto SI, Dragone G and Roberto IC (2006) Brewers' spent grain: generation, characteristics and potential applications. Journal of Cereal Science 43, 1-14.

Pape T, Blagoderov V and Mostovski MB (2011) Order Diptera linnaeus, 1758. In Zhang ZQ (Ed.), Animal Biodiversity: An Outline of Higher-Level Classification and Survey of Taxonomic Richness, Vol. 3148. Auckland, New Zealand Magnolia Press, Zootaxa, pp. 222-229.

Pérez-Bañón C, Rojo S, Ståhls G and Marcos-García M (2003) Taxonomy of European Eristalinus (Diptera: Syrphidae) based on larval morphology and molecular data. European Journal of Entomology 100, 417-428.

Pérez-Bañón C, Petanidou T and Marcos-García MA (2007) Pollination in small islands by occasional visitors: the case of Daucus carota subsp. commutatus (Apiaceae) in the Columbretes archipelago, Spain. Plant Ecology 192, 133-151.

Reddy GVP and Chi H (2015) Demographic comparison of sweetpotato weevil reared on a major host, Ipomoea batatas, and an alternative host, I. triloba. Scientific Reports 5, 1-9.

Rotheray GE (1993) Colour Guide to Hoverfly larvae (Diptera, Syrphidae) in Britain and Europe. Dipterist Digest No. 9. Sheffield, UK: Derek Whiteley.

Saeed S, Sajjad A, Kwon O and Kwon YJ (2008) Fidelity of hymenoptera and Diptera pollinators in onion (Allium cepa L.) pollination. Entomological Research 38, 276-280.

Sajjad A and Saeed S (2010) Floral host plant range of syrphid flies (Syrphidae: Diptera) under natural conditions in southern Punjab, Pakistan. Pakistan Journal of Botany 42, 1187-1200.
Sedighi L, Aghdam HR, Imani S and Shojai M (2017) Age-stage two-sex life table analysis of Sesamia nonagrioides (Lep.: Noctuidae) reared on different host plants. Archives of Phytopathology and Plant Protection 50 438-453.

Smucker MD, Allan J and Carterette B (2007) A Comparison of statistical significance tests for information retrieval evaluation. in Proceedings of the Sixteenth ACM Conference on Information and Knowledge Management, Lisbon, Portugal, 6-8 November 2007, pp. 623-632. New York, NY, USA: Association for Computing Machinery.

Sommaggio D (1999) Syrphidae: can they be used as environmental bioindicators? Agriculture, Ecosystems and Environment 74, 343-356.

Speight MCD (2020) Species accounts of European Syrphidae, 2020. In Speight MCD, Castella E, Sarthou JP \& Vanappelghem C (Eds.), Syrph the Net, the Database of European Syrphidae (Diptera). Dublin, Ireland: Syrph the Net publications, pp. 79-87.

Ssymank A, Kearns CA, Pape T and Thompson FC (2008) Pollinating flies (Diptera): a major contribution to plant diversity and agricultural production. Biodiversity 9, 86-89.

Stojceska V, Ainsworth P, Plunkett A and Ibanoglu S (2008) The recycling of Brewer's processing by-product into ready-to-eat snacks using extrusion technology. Journal of Cereal Science 47, 469-479.

Szponar B, Pawlik KJ, Gamian A and Dey ES (2003) Protein fraction of barley spent grain as a new simple medium for growth and sporulation of soil actinobacteria. Biotechnology Letters 25, 1717-1721.

Tanács L, Benedek P, Monostori T and Bodnar K (2008) Pollinating insect assemblages of seed onion fields at the traditional onion growing area of Makó. Research Journal of Agricultural Science 40, 515-520.

Thomas KR and Rahman PKSM (2006) Brewery wastes. Strategies for sustainability: a review. Aspects of Applied Biology 80, 147-153.

Thompson FC and Rotheray GE (1998) Family Syrphidae. In Papp L \& Darvàs B (Eds.), Contribution to A Manual of Palaearctic Diptera. Vol. 2. Budapest, Hungary: Science Herald, pp. 81-139.

Thompson, FC, Rotheray, GE and Zumbado, MA (2010) Syrphidae (flower flies). In Brown BV, Borkent A, Cumming JM, Wood DM, Woodley NE \& Zumbado MA (Eds.), Manual of Central American Diptera. Vol. 2. Ottawa, Canada: NRC Research Press, pp. 763-792.

Tuan SJ, Lee CC and Chi H (2014a) Population and damage projection of Spodoptera litura (F.) on peanuts (Arachis hypogaea L.) under different conditions using the age-stage, two-sex life table. Pest Management Science 70, 805-813.

Tuan SJ, Lee CC and Chi H (2014b) Erratum to population and damage projection of Spodoptera litura (F.) on peanuts (Arachis hypogaea L.) under different conditions using the age-stage, two-sex life table. Pest Management Science 70, 1936

Tuan SJ, Chang PW, Saska P, Atlihan R and Chi H (2017) Host plants mixture and fitness of Kolla paulula: with an evaluation of the application of Weibull function. Journal of Applied Entomology 141, 329-338.

Weldon CW, Mnguni S, Démares F, du Rand EE, Malod K, Manrakhan A and Nicolson SW (2019) Adult diet does not compensate for impact of a poor larval diet on stress resistance in a tephritid fruit fly. Journal of Experimental Biology 222, jeb192534. 